\title{
Communicating in Product Harm Crises: Do the Right
}

\section{Thing}

\author{
Paola Cane
}

Mia Solution srl, Torino 10122, Italy

\begin{abstract}
Food recalls can have very serious aftermath from many points of view: starting from the outbreak consequences on public health, on company's reputation, sell-out, finance, up to putting at risk the survival of the firm itself. From a formal point of view, a product harm crisis presents similarities with other emergency situations: both of them consist in unpredictable events, often due to unknown or undervalued causes, which can significantly alter normal business and compromise the safety of the company, of its employees and customers. Given the potential damage resulting from a dangerous product crisis, it is surprising that in the food industry alongside mere procedures (often reducible to botched manuals compiled solely because their presence reassures auditors and authorities) there is still little attention to an approach based on a method. Formal corporate procedures (manuals and crisis management plans) are important, but can cause a false sense of security and preparedness, if executives do not possess an adequate crisis management culture, which depends, as well as on experience and training, also on the ability to assume the correct behavioral posture, and which involves psychological, organizational and communicational skills that can not be undervalued. The purpose of this article is to provide a practical approach based on the experience of crisis-management (applied in emergency situations by health professionals, armed forces and civil protection) useful to support food industry during a food recall, in order to avoid the most classic errors that can undermine speed of reaction, corrective measures effectiveness and leadership, in the most delicate moments for a company life. If it is true the way a firm manages the recall affects its impact, it is necessary to assess the fundamental factors to be observed at such times: timeliness, lucidity, responsibility, leadership.
\end{abstract}

Key words: Communication management, crisis communication, product harm crises, recall.

\section{Introduction}

It is commonly accepted that product recalls can have a terrible impact on brand confidence, sales and pricing and, in some cases, the survival of the firm itself can be at risk [1-4]. Above all, let us mention the infamous case of Topps, the second largest US maker of frozen hamburgers that declared bankrupt just few days after recalling 21.7 million pounds of frozen patties contaminated with E. coli on September 2007.

Product harm crises can extend their negative impact to the whole product category, as the inadequacy of the production process can be perceived to be an industry-wide problem [5-6]. If during the prolonged out-of-stock situation often associated with the product recall, customers may switch to competing

Corresponding author: Paola Cane, doctor, research fields: food law and safety. brands, or even decide to quit buying the category, some case histories show emblematically that product harm crises effects are not limited to the company involved, but can dramatically damage the whole sector, including the competitors that try to take advantage of the ongoing rival's crises [7]. In the same way, in June 1996, when Kraft Foods recalled its two peanut-butter products, due to more than 100 cases of salmonella poisoning, its main competitor Sanitarium took advantage of the crisis by investing in massive advertising campaigns that stated that it had been roasting its own peanuts to avoid foodborne outbreaks. Even if Sanitarium's market share increased from 15 to 70 percent during the crisis period, the overall demand for peanut-butter went down by almost $30 \%$ due to a general distrust in the whole segment.

Successfully handling a crisis is therefore essential. 
Product harm crises, by definition, take on very different connotations and require heterogeneous strategies, tones and communication tools [4].

Classically company's responses to crises are divided into four different grades:

- Denial: the company simply denies any responsibility for a defective product;

- Involuntary recall: the company recalls the product only under authority order;

- Voluntary recall: the company chooses to recall the product prior to authority intervention in application of the precautionary principle;

- Super effort: the company responds by being socially responsible, transparent and proactive.

Whatever strategy a firm embraces, corporate communication during crises can be divided into two phases: the phase of the initial response, and the phase of reputation recovery [8]. Especially in the first phase, communication can actively and concretely contribute to public health protection, playing a decisive role in limiting material damage to consumers and, consequently, to the company: moreover, the better the first phase will be managed, the easier it will be to regain consumer's trust and the market shares. Evidence indicates that a recall may either improve the company's image, if it adopts a socially responsible attitude and is consistent and coherent in its communication and transparent in its relationships with media and consumers [9-10]. That is why communication-from the first moments—shall be fast, accurate, direct, informative and transparent.

\section{Procedures vs. Method}

Many companies use crisis management plans to prepare management paths for them: these plans are often focused on procedures aimed at imposing the acquisition of operating routines. Among managers, the illusion of invulnerability given by the presence of prevention and crisis management procedures can be at least as harmful as a risk appetite that is too high.
Not only that, the habit of being guided by rigorously defined procedures can lead operators to paralysis in the face of unexpected processes from the scheme. If the procedures are an effective tool for managing certain aspects (for example notifications to alert systems and competent authorities), in drafting the crisis management plan it is preferable not to limit oneself to them, but to suggest a working method, i.e. a logical, organizational and mental structure to manage and resolve the emergency, which can be useful above all in those situations which, in so far as they are unpredictable, are not proceduralized. This is because the unpredictable can not always be foreseen: it is therefore extremely important that the crisis management plan provides a methodological approach since only the acquisition of a method, in fact, makes it possible to face completely unknown situations, operating in conditions of stress and of urgency. Acquiring a method takes time, training and metabolization, but it is worth investing efforts in this direction.

\section{Timeliness}

Speed and timeliness are crucial elements in dealing with crisis scenarios that, by definition, are changeable: the collection and updating of data, the transmission of the flow of information, the decisions and the corrective actions that follow must be fast. In conditions of absolute emergency there is no time to plan: in times of crisis we act. However, in view of the necessary readiness to take corrective action it is necessary to avoid the risk of making hasty decisions, based on incomplete or inaccurate information, on which, on the contrary, long-term effects may depend. Small companies are generally faster, more flexible and more capable of reacting in a shorter time. This depends, in part, on the greater flexibility of smaller corporate structures, but also on a greater sensitivity to pre-alarms, which are often ignored in large companies. 


\section{The Golden Hours}

The first hours of any crisis, called the "Golden Hours", are the most delicate moments, when most organizations fail, mostly because they underestimate the media attention crisis communication plan to follow. The need for an immediate response is even more important nowadays where social media impose a time that did not exist a few years ago: the "real time".

Giving out information in the golden hours is very important especially when a crisis deals with public safety: consumers and stakeholders need to know how to avoid risks and what actions are needed [11].

Considered that crises scenarios are by definition changeable, speed and timeliness are crucial elements in addressing crisis communication: as we previously said, the collection and updating of data, the information flow, the decisions and the corrective actions that follow shall be quick. The crisis of Trans World Airways (TWA) flight 800 provides with an example of lack of quick communication to the passengers' families that kept the company under a negative media spotlight for months. Delays in communicating can have devastating consequences: in 1986, Audi was pressured to respond to a recall request made by the Center for Auto Safety to the U.S. National Highway Traffic Safety Administration (NHTSA), because of a number of car accidents involving injury and death apparently linked to a technical flaw of Audi 5000S. Audi delayed its response for three months. Then it announced that it would replace the idle stabilization valve and relocate the brake and gas pedals on 132,000 Audi 5000s. However, in its July 1986 recall, instead of performing those tasks, Audi installed a gear shift lock that required drivers to depress the brake before shifting into gear. The cost of the recall to Audi was estimated at $\$ 25$ million, which is almost the typical of costs for automotive recalls of that scale.

Consequently, Audi sales, which had reached 74,061 in 1985, collapsed to 12,283 in 1991 and remained level for years, with resale values falling dramatically dropped 80 percent over the next five years. It was not until 2000 that it regained its peak from 1985.

\section{Buy Time Communication}

Even if readiness is required, it is necessary to avoid the risk of making hasty statements based on inaccurate or rough information, on which long-term effects may depend. On the other hand, in the middle of a harmful event, it may be necessary to communicate to the public even before having precise information. Ignoring who demands answers will worsen the situation: journalists, consumers and social networks would end up by filling the silence autonomously. The Audi case history gives us another eloquent example: soon after the recall an adverse television report, 60 Minutes, plunged the knife in and again, reporting unintended acceleration, while the brake pedal was depressed. Subsequent investigation revealed that 60 Minutes had engineered the vehicle's behavior. Again Audi reacted too late, even when the investigation was debunked the damage was done. In order to avoid such cases, companies might implement a "Buy-Time Communication", to reassure that the attention is high, reduce any tension, and avoid a flowering of illations, to demonstrate their commitment. Ignoring attacks can worsen the situation.

\section{Apologies and Voluntary Recalls}

In order to protect a firm's reputation apology and voluntary product recalls are often employed as a responsible crisis response to show a company's concern to public safety. An apology is a form of acceptance of crisis responsibility, which makes an organization more honorable and enables it to reduce the likelihood of negative responses [12-13]. Admitting mistakes publicly can be difficult and even painful, but it is not perceived as a sign of weakness. Also the decision to provide for a voluntary recall can 
be difficult as, in many cases, recall can lead to very costly activities and sell out loss and decision makers suffer the pressure of profit and performance. Nevertheless, in many circumstances apologies and admitting mistakes can help rebuilt the relationship with authorities, customers and consumers. Oppositely, public denial can be interpreted as arrogant and unreliable, two qualities that no company would like to be associated with its image. When crafted properly, an apology is not a liability, it is an asset: it can attenuate the effects of the crises or even turn it into the opportunity of enhancing the company ethic and positively influencing consumer's judgment and trust. Some studies indicate that a recall may either improve the company's image, if it adopts a socially responsible attitude and is consistent and coherent in its communication and transparent in its relationships with media and consumers [9-10]. In fact, in terms of apologies, many previous literatures underlined that the use of apology to salvage a reputation was the preferred strategic option in crisis communications. The history of recent recalls presents some significant cases of crisis management through a structured strategy that includes apology and voluntary recalls: among these it is worth mentioning the Toyota 2000 recall. In that case, Akio Toyota wrote personally his apology stating "All the Toyota vehicles bear my name. When the cars are damaged, it is though I am, as well. Toyota has, for the past few years, been expanding its business rapidly. Quite frankly, I fear the pace at which we have grown may have been too quick. I regret that this has resulted in the safety issues described in the recalls we face today, and I am deeply sorry for any accidents that Toyota drivers have experienced".

To understand the tenor of these declarations we can not disregard the cultural context in which they occurred, and the importance that apologies assume in Japanese culture. However, it is useful to point out that, while assuming responsibility for what happened, the Toyota president managed to distance himself from the conduct that led to the recall and to show the willingness to proceed in a different direction.

A successful apology can turn a negative experience into a positive one, an upset customer into a loyal one, and a bad reputation into a great one. Regarding the responsibility for errors, it is good to remember that the attitude of "witch-hunting" which, often, occurs in companies alongside a harm product crisis is deleterious. In the midst of an emergency, looking for the subject to blame is never a good strategy, at the opposite, it could persuade the responsible to hide information necessary for decision-making, in an attempt to escape the pillory.

\section{The Human Voice}

Communication during crisis shall be trustworthy and credible, transparent and reassuring, and should not only contain facts and information, including what is being done and what is going to be done, but it might show caring, compassion, and empathy to create public goodwill and maintain a positive reputation for the organization. While the company is exposed to the media and social networks, to the judgment of members and all stakeholders, but above all it is exposed to legal responsibilities, communicating requires the maximum commitment both in rational area, both in the emotional one. While communicating the company might be expected to show empathy in its response. Anxiety, fear and stress are human emotional reactions, which can be considered absolutely natural, but they shall not take the upper hand, nor guide communication responses, since they not only do not contribute to the achievement of the objective. By communicating it is necessary to keep in mind that what we say is addressed to a wide range of interlocutors with different information needs and interests, which tend to vary during the evolution of the crisis. Understanding the needs, the cultural background, the history of your audience is one of the most important factors, as it helps to make communication effective. 
Communication efforts, therefore, but shall be shaped consistently with the interlocutors, trying to sound personal and sincere. Attention to the public is extremely important as there are victims or injured people. Moreover, communication has to be extremely attentive when the crisis affects delicate categories of consumers. Some examples emerge from the study of the recalls regarding products intended for children, both in the food sector (i.e. powdered milk or infant formula) or toys for early childhood. When in July 2007 Mattel recalled 19 millions toys which were found evidence of toxic lead paint, its CEO Robert Eckert, responsible to communicate, found the right words to communicate with retailers and parents that the company truly understood it had violated trust and that it was determined to make it right.

\section{Engage a Dialogue}

Crisis communication has been defined as "dialogue between the organization and its public prior to, during, and after the negative occurrence" [13]. Establishing relationships with stakeholders and engaging in a mutual dialogue will build trust that can protect the organization when the crisis hits $[10,14]$. Johnson \& Johnson's crisis management procedures during the 1982 Tylenol recall are still today, after thirty years, a reference model. Massive communication was prepared, directed at physicians, hospitals, retailers and distributors aimed at explaining risks and withdrawal procedures. Not only that, but the CEO J. Burke became in the days of the crisis, the face of the same: he was collaborating with the press, showing himself and the company as responsible and available interlocutor, open and proactive, establishing the company communication as a source of accurate and reliable information, at the point that the media recognized the company and its delegates the role of supporting and integrating the declarations of the federal authorities.

\section{Conclusion}

This article outlined some of the most important communication skills required in the first phase of response of a product harm crisis, providing a general roadmap to relevant communication strategies based on the analysis of specific case histories, which it might be important to consult and keep in mind during actual events. The robustness of this analysis is subject to even further scrutiny across time, and more refined data about measuring the impact of proper or improper communication strategies remain the topic of further investigation.

\section{References}

[1] Van Heerde, H., Helsen, K., and Dekimpe, M. 2007. "The Impact of a Product-Harm Crisis on Marketing Effectiveness.” Marketing Science 26 (2): 230-45.

[2] Laufer, D., and Coombs, W. T. 2006. "How Should a Company Respond to a Product Harm Crisis? The Role of Corporate Reputation and Consumer-Based Cues.” Business Horizons 49 (5): 379-85.

[3] Rhee, M., and Haunschild, P. R. 2006. "The Liability of Good Reputation.” Organization Science 17 (1): 101-17.

[4] Siomkos, G. J. 1989. "Managing Product-Harm Crisis." Industrial Crisis Quarterly 3 (1): 41-60.

[5] Chen, Y., Ganesan, S., and Liu, Y. 2009. “Does a Firm's Product Recall Strategy Affect Its Financial Value? An Examination of Strategic Alternatives during Product-Harm Crises.” Journal of Marketing 73 (6): 214-26.

[6] Verbeke, W., Ward, R. W., and Viaene, J. 2000. "Probit Analysis of Fresh Meat Consumption in Belgium: Exploring BSE and Television Communication Impact.” Agribusiness 16: 215-34.

[7] Mowen, J. C., Jolly, D., and Nickell, G. S. 1981. "Factors Influencing Consumer Responses to Product Recalls: A Regression Analysis Approach.” Advances in Consumer Research 8: 405-7.

[8] Coombs, T. 1999. "Information and Compassion in Crisis Responses: A Test of Their Effects.” Journal of Public Relations Research 11 (2): 125-42.

[9] Siomkos, G. J. 1999, “On Achieving Exoneration after a Product Safety Industrial Crisis.” Journal of Business \& Industrial Marketing 14: 17-9.

[10] Magno, F., Cassia, F., and Marino, A. 2010. "Exploring Customers' Reaction to Product Recall Messages: The Role of Responsibility, Opportunism and Brand Reputation.” Presented at Global Conference on Business \& Economics 2010, Roma.

[11] Fearn-Banks, K. 2007. Crisis Communication: A 
Casebook Approach. Mahwah, NJ: Lawrence Erlbaum Associates.

[12] Hammel, M., Yamada, Y., Ponchio, M. C., Cordeiro, R. A., and Strehlau, V. I. 2016. "The Influence of Product Recall on Consumer Loyalty Influência Do Recall De Produtos Sobre A Lealdade Do Consumidor.” Revista de Administração da UNIMEP 14 (1): 143-64.

[13] Magno, F. 2012. "Managing Product Recalls: The Effects of Time, Responsible vs. Opportunistic Recall Management and Blame on Consumers' Attitudes.” Procedia Social and Behavioral Sciences 58: 1309-15.

[14] De Alessi, L., and Staaf, R. J. 1994. "What Does Reputation Really Assure? The Relationship of Trademarks to Expectations and Legal Remedies.” Economic Inquiry 32: 477-85. 